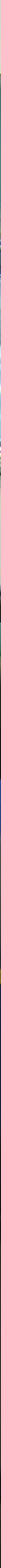




\begin{tabular}{|c|c|c|c|c|}
\hline$\Omega$ & 0 & & $\equiv$ & (2) \\
\hline $\begin{array}{l}\text { Zafeiris Louvaris' } \\
\text { loannis Vogiatzis }^{1,2,3}\end{array}$ & $\begin{array}{l}\text { 'Faculty of Physical } \\
\text { Education and Sports } \\
\text { Sciences, National and } \\
\text { Kapodistrian University of } \\
\text { Athens, Athens, Greece } \\
{ }^{2} 1 \text { st Dept of Respiratory } \\
\text { Medicine, Pulmonary } \\
\text { Rehabilitation Unit, } \\
\text { National and Kapodistrian } \\
\text { University of Athens, }\end{array}$ & $\begin{array}{l}\text { Sotiria Hospital, Athens, } \\
\text { Greece } \\
{ }^{3} \text { sst Dept of Critical Care } \\
\text { Medicine, Pulmonary } \\
\text { Rehabilitation Center, } \\
\text { National and Kapodistrian } \\
\text { University of Athens, } \\
\text { Evangelismos Hospital, } \\
\text { Athens, Greece }\end{array}$ & $\begin{array}{l}\text { loannis Vogiatzis, } \\
\text { Thorax Foundation, 3str } \\
\text { Ploutarhou 10675, Athens, } \\
\text { Greece }\end{array}$ & gianvog@phed.uoa.gr \\
\hline
\end{tabular}

\section{Physiological basis of cardiopulmonary rehabilitation in patients with lung or heart disease}

\section{Summary}

Shortness of breath associated with cardiorespiratory abnormalities and peripheral muscle discomfort are the major factors that limit exercise capacity in patients with chronic obstructive pulmonary disease (COPD) and those with congestive heart failure (CHF). Both of these symptoms negatively impact on patients' daily physical activity levels. In turn, poor daily physical activity is commonly associated with increased rates of morbidity and mortality. Cardiopulmonary rehabilitation programmes partially reverse muscle weakness and dysfunction and increase functional capacity in both COPD and CHF. However, benefits gained from participation in cardiopulmonary rehabilitation programmes are regressing soon after the completion of these programmes. Moreover, several barriers limit access and uptake of cardiopulmonary rehabilitation programmes by eligible patients. A potential solution to the underutilisation of cardiopulmonary rehabilitation is the implementation of tele-rehabilitation interventions at home using information and communications technologies. Thus, tele-rehabilitation may be useful to encourage and educate patients with COPD or $\mathrm{CHF}$ on how best to maintain and/or further enhance daily physical activity levels.

\section{Introduction}

Although exercise capacity is limited in patients with chronic obstructive pulmonary disease (COPD) and those with congestive heart failure
(CHF), there is clear evidence that the systemic consequences of these disease entities negatively impact on daily physical activity levels [1-9].

Along these lines, it is well documented that in patients with COPD, daily physical
Conflict of interest

None declared. 
activity levels are significantly reduced compared with those in healthy individuals even during the early course of the disease [10]. Specifically, time spent in walking is on average $47 \%$ less, whilst intensity of daily activities adopted by COPD patients is on average $25 \%$ lower compared with those recorded in age-matched healthy individuals [2]. Reduced levels of daily physical activity in patients with COPD are associated with a faster rate of disease progression and increased rates of hospital admissions and mortality [11, 12].

Similarly, in patients with $\mathrm{CHF}$, daily physical activity levels are significantly lower compared with daily activity recommendations set by the World Health Organization (WHO). A reduced level of daily activity has been shown to constitute a more powerful index to predict mortality compared with laboratory-based exercise testing variables, such as peak oxygen uptake and exercise endurance time $[6,13,14]$.

Consequently, relative inactive patients with COPD or $\mathrm{CHF}$ experience more intense symptoms when they engage in activities of daily living. Due to the unpleasant nature of dyspnoea and leg discomfort, these patients tend to avoid such activities, eventually becoming less active $[15,16]$. This vicious circle can be distressing to patients and leads to a profound reduction in health-related quality of life. Along these lines, exercise training aiming at improving exercise capacity induces a reduction in exercise-induced symptoms, thereby increasing exercise tolerance $[17,18]$. Whether improved exercise capacity readily translates into improved daily physical activity is still an issue of intense investigation and debate [19].

The present article describes the physiological rationale of cardiopulmonary rehabilitation programmes for patients with COPD or $\mathrm{CHF}$, whilst it focuses on a novel interventional approach aiming at enhancing daily physical levels with the use of tele-rehabilitation strategies.

\section{Common underlying mechanism of exercise limitation}

Despite the fact that the primary system of impairment is different in patients with COPD and those with CHF (i.e. ventilatory and gas exchange limitations in COPD, central haemodynamic abnormalities in $\mathrm{CHF}$ ), leg discomfort is very often the predominant complaint reported during exercise in both disease entities.

The origin of leg discomfort is due to a number of histological and metabolic alternations manifested in peripheral muscles of these patients, namely 1) peripheral muscle atrophy across all fibre types, 2) shift from type I oxidative to type II glycolytic muscle fibres, 3) decrease in aerobic enzyme activity and mitochondrial volume density and 4) decrease in muscle capillary density [2O-23]. The above alternations reduce muscle oxidative potential, regional muscle blood flow and muscle oxygen delivery to the peripheral muscles, thereby accelerating the occurrence of peripheral muscle fatigue during exercise [20-23]. As far as dyspnoea symptoms are concerned, previous findings show that in both disease entities exercise-induced metabolic acidosis increase respiratory drive thereby intensifying dyspnoea sensations [24-27].

Regular exercise training can partly reverse the aforementioned peripheral muscle abnormalities [28-30]. Indeed, there is strong evidence that in patients with COPD or CHF, participation in cardiopulmonary rehabilitation programmes induces significant peripheral muscle adaptations that mitigate the intensity of locomotor muscle discomfort and dyspnoea sensations during exercise [31, 32] (table 1).

Table 1 Similar benefits of cardiopulmonary rehabilitation in COPD and CHF

\begin{tabular}{l}
\hline Improves functional capacity \\
\hline $\begin{array}{l}\text { Lessens the intensity of breathing and } \\
\text { locomotor muscle discomfort }\end{array}$ \\
\hline Improves health-related quality of life \\
\hline Increases musculoskeletal blood flow \\
\hline $\begin{array}{l}\text { Increases oxidative and metabolic muscle } \\
\text { capacity }\end{array}$ \\
\hline $\begin{array}{l}\text { Attenuates and/or reverses skeletal muscle } \\
\text { atrophy }\end{array}$ \\
\hline Improves autonomic activation \\
\hline Increase in endothelial function \\
\hline Improves muscle performance \\
\hline
\end{tabular}




\section{Cardiopulmonary rehabilitation programmes}

Physical exercise training is the cornerstone of any cardiopulmonary rehabilitation programme (table 2). Exercise training sessions may combine aerobic and resistance muscle training sessions. Aerobic exercise training can be either continuous or interval. In addition resistance training consists of arm, leg and trunk exercises (fig. 1) [17, 18, 33].

In view of the fact that intensity of the exercise training stimulus is a critical determinant of the magnitude of physiological adaptations that occur in response to training, high intensity continuous exercise training may not be feasible for those COPD or CHF patients who are unable to sustain high intensities for long periods of time due to symptom limitations [34].

Accordingly, it has been documented that when exercising loads are applied intermittently (i.e. alternating periods of high intensity exercise by resting periods or periods of lowerintensity exercise), COPD as well as $\mathrm{CHF}$ patients can tolerate high work rates $(100 \%$ of peak work rate) with lower metabolic and cardiorespiratory demands (table 3) [34, 35]. Indeed, when COPD patients exercised for short period of time (e.g. $30 \mathrm{~s}$ ) alternated with equal periods of rest intervals, patients were able to complete the total amount of work with lower symptoms of dyspnoea and leg discomfort compared with moderate constant-load exercise training [36]. Delayed occurrence of lactic acidosis observed during interval exercise appears to be beneficial by reducing respiratory drive, thereby lowering dyspnoea sensations and the occurrence of peripheral muscle fatigue [36]. Thus, interval exercise is more affordable by patients with advanced

Table 2 Components of cardiopulmonary rehabilitation

Exercise training sessions (including aerobic and resistance training)

Medical therapy assessment and optimisation

Respiratory physical therapy and breathing techniques

Psychological support and behavioural management

Diet and nutritional counselling

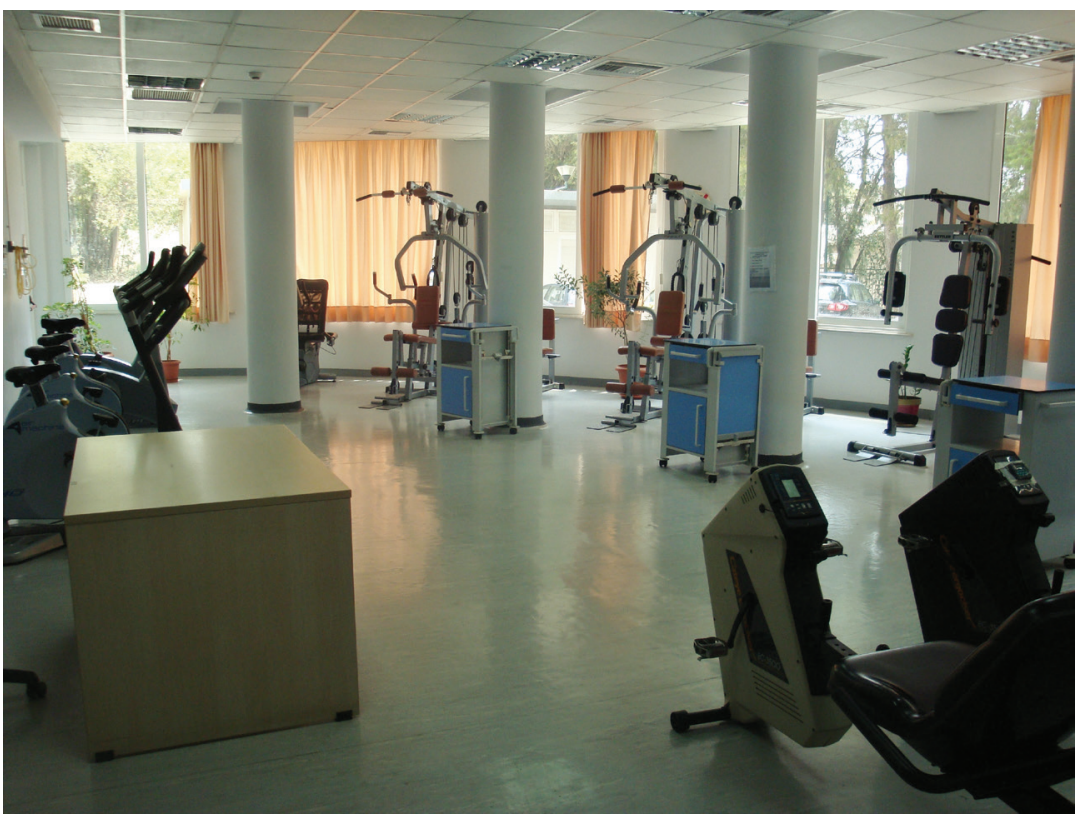

Figure 1

View of the Pulmonary Rehabilitation Unit at Athens University Medical School - First Department of Respiratory Medicine, Sotiria Hospital, showing necessary apparatus to administer hospital-based cardiopulmonary rehabilitation programmes.

disease. In addition, the magnitude of training improvements in functional capacity, morphological and typological muscle adaptations is not different to that obtained following conventional constant-load training [36]. In patients with $\mathrm{CHF}$, interval exercise training has been shown to induce superior effects to those of constant-load exercise in terms of improving aerobic capacity, aortic dilatation capacity and augmented systolic pressure in parallel with improvement in left ventricular diastolic function and endothelial function, thereby lessening the ventilatory requirement and thus the intensity of perceived dyspnoea [35].

There are studies reporting that cardiopulmonary rehabilitation programmes have positive effects on daily physical activity levels in patients with COPD or CHF. Specifically, a number of studies using either short

\section{Table 3 Benefits of interval exercise training in COPD and $\mathrm{CHF}$}

Prolongs exercise duration

Lowers cardiovascular demand

Lowers ventilatory requirement

Allows higher exercise intensity

Reduces symptoms of dyspnoea and leg discomfort 
( 3 weeks) or longer-term (18 weeks) exercise programmes, demonstrated a significant increase in daily physical activity levels following the completion of aerobic and/or resistant supervised training programmes [37-40]. On the other, there have been numerous studies that failed to show significant effects of conventional exercise training on daily physical activity levels [41-43].

\section{The potential of telemedicine interventions}

While the benefits of participation in a cardiopulmonary exercise programme are important in patients with COPD or CHF, these benefits are reversible and can be attenuated few weeks after completion of the rehabilitation programme. Furthermore, hospital-based programmes are generally resource demanding and are limited by low adherence rates. In a recent study, representatives of 430 centres from 40 countries completed a global survey in regards to the content and organisational aspects of cardiopulmonary rehabilitation in patients with COPD [44]. The results of the survey showed that, in terms of patient numbers, only a small fraction of COPD patients enrolled to rehabilitation programmes per year (fig. 2) [44]. In addition, a systematic review attempted to identify the barriers to uptake and completion of cardiopulmonary rehabilitation programmes [45]. The review reported that on average $10-30 \%$ of enrolled participants failed to complete a cardiopulmonary rehabilitation programme due to a number of barriers, including lack of family support, depression, transport difficulties, lack of perceived benefit by the patient, inconvenient timing or disruption of established routine of the patients [45].

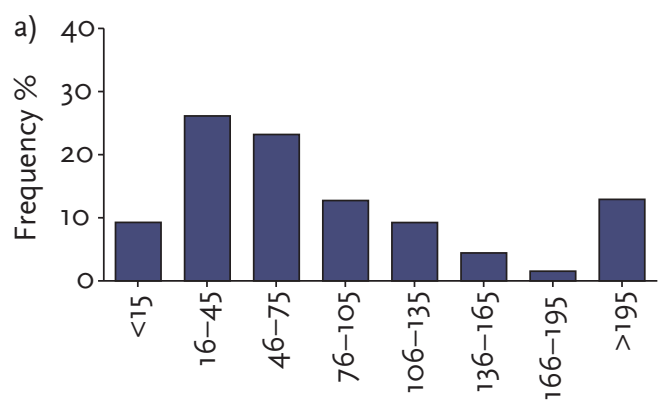

Individuals who enrolled in PR

Figure 2

Estimated number of individuals who enrolled in each pulmonary rehabilitation (PR) programme in 2011 [44].
Accordingly, alternative models for providing pulmonary rehabilitation should be undertaken in order to improve its access and uptake. Tele-rehabilitation, which links expert rehabilitation healthcare providers with others at remote sites or with patients in their homes, has the potential to improve access. Initial small-scale studies demonstrate feasibility and suggest that clinical benefits may be achievable [46-49]. Consequently, interactive remote monitoring services using information and communication technologies (ICT) may be useful as interventions for maintaining and/or increasing physical capacity in patients with COPD or CHF.

\section{Tele-coaching programme to enhance physical capacity in COPD and CHF}

Interactive remote monitoring interventions allow clinicians and doctors to check a patient remotely with reference to physiological signs, symptoms and activity levels using a wide range of technological equipment. The efficacy of these home-based tele-monitoring programmes has been evaluated in patients with COPD or $\mathrm{CHF}$ and the results show significant increase in clinical, functional and quality of life status [50-55]. Besides improvement in health status in patients with COPD or CHF, the major clinical important finding derived from these studies is that this kind of intervention is associated with decreasing rates of hospital readmissions secondary to cardiovascular events or due to COPD exacerbations [53, 56-59].

Such an interactive remote physical training intervention is currently under investigation in patients with COPD aiming at enhancing and maintaining daily physical activity levels (www. proactivecopd.com/about/news/telecoaching-to-enhance-physical-activity/). A 3-month coaching intervention including a step counter, an exercise booklet, an application installed on a smartphone device, text messages and telephone contact with investigators when necessary is underway. An example of the basic components is shown on figure 3.

Preliminary results from tele-rehabilitation studies in COPD or CHF show good compliance with the ICT along with improvement in daily physical activity levels [51, 54, 6o-62]. However more studies are warranted to establish whether carefully structured 
Data transmitted to central base via telephone network

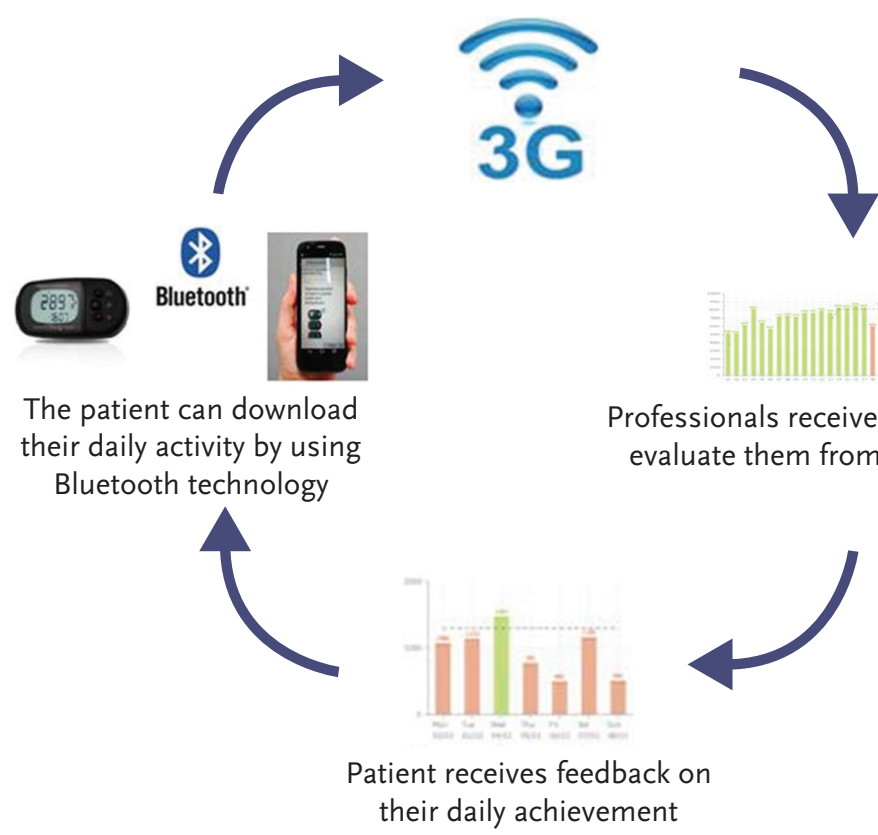

Figure 3

Example of the basic components of tele-coaching programme.

home-based tele-rehabilitative programmes are feasible, effective and lead to long-term training adaptations as well as an adoption of health-enhancing behavior, such as regular physical activity.

\section{Conclusions}

Despite the fact that the primary system impairment is different in patients with COPD or CHF, the underlying symptoms reported by these patients during exercise are common and are related predominantly to leg discomfort but also to shortness of breath. Cardiopulmonary rehabilitation programmes significantly increase functional capacity in patients with COPD or CHF but their effects are rapidly attenuated after the completion of the programme. Interestingly, home-based interventions using tele-monitoring equipment may constitute a promising intervention to maintain and/or further improve physical capacity in patients with COPD or CHF.

\section{References}

1. Pitta F, Troosters T, Spruit MA, et al. Characteristics of physical activities in daily life in chronic obstructive pulmonary disease. Am J Respir Crit Care Med 2005; 171: 972-977.

2. Vorrink SN, Kort HS, Troosters T, et al. Level of daily physical activity in individuals with COPD compared with healthy controls. Respir Res 2011; 12: 33.

3. Troosters T, Sciurba F, Battaglia S, et al. Physical inactivity in patients with COPD, a controlled multi-center pilot-study. Respir Med 2010; 104: 1005-1011.

4. Watz H, Waschki B, Meyer T, et al. Physical activity in patients with COPD. Eur RespirJ 2009; 33: 262-272.

5. Garcia-Aymerich J, Serra I, Gomez FP, et al. Physical activity and clinical and functional status in COPD. Chest 2009; 136: 62-70.
6. Walsh JT, Charlesworth A, Andrews R, et al. Relation of daily activity levels in patients with chronic heart failure to long-term prognosis. Am J Cardiol 1997; 79: 1364-1369.

7. Hoodless DJ, Stainer K, Savic N, et al. Reduced customary activity in chronic heart failure: assessment with a new shoe-mounted pedometer. Int J Cardiol 1994; 43: 39-42.

8. Toth MJ, Gottlieb SS, Goran MI, et al. Daily energy expenditure in free-living heart failure patients. Am J Physiol 1997; 272: 469-475.

9. Oka RK, Stotts NA, Dae MW, et al. Daily physical activity levels in congestive heart failure. Am J Cardiol 1993; 71: 921-925. 
10. Van Remoortel H, Hornikx M, Demeyer H, et al. Daily physical activity in subjects with newly diagnosed COPD. Thorax 2013; 68: 962-963.

11. Garcia-Aymerich J, Serra I, Gomez FP, et al. Physical activity and clinical and functional status in COPD. Chest 2009; 136: 62-70.

12. Garcia-Aymerich J, Lange P, Benet M, et al. Regular physical activity reduces hospital admission and mortality in chronic obstructive pulmonary disease: a population based cohort study. Thorax 2006; 61: 772-778.

13. Wannamethee SG, Shaper AG, Walker M. Physical activity and mortality in older men with diagnosed coronary heart disease. Circulation 2000; 102: 1358-1363.

14. Wannamethee SG, Shaper AG, Walker M. Changes in physical activity, mortality and incidence of coronary heart disease in older men. Lancet 1998; 351: 1603-1608.

15. Jennines $\mathrm{CL}$, Esler MD. Circulators regulation at rest and exercise and the functional assessment of patients with congestive heart failure. Circulation 1990; 81: 5-13.

16. Troosters $\mathrm{T}$, van der Molen T, Polkey M, et al. Improving physical activity in COPD: towards a new paradigm. Respir Res 2013; 14: 115.

17. Troosters T, Casaburi R, Gosselink R, et al. Pulmonary rehabilitation in chronic obstructive pulmonary disease. Am J Respir Crit Care Med 2005; 172: 19-38.

18. Jonsdottir S, Andersen KK, Sigurosson AF, et al. The effect of physical training in chronic heart failure. Eur J Heart Fail 2006; 8: 97-101.

19. Watz H, Pitta F, Rochester CL, et al. An official European Respiratory Society statement on physical activity in COPD. Eur Respir J 2014; 44: 1521-1537.

20. American Thoracic Society and European Respiratory Society. Skeletal muscle dysfunction in chronic obstructive pulmonary disease. A statement of the American Thoracic Society and European Respiratory Society. Am J Respir Crit Care Med 1999; 159: $\mathrm{S}_{1}-\mathrm{S}_{40}$

21. Maltais F, Simard AA, Simard C, et al. Oxidative capacity of the skeletal muscle and lactic acid kinetics during exercise in normal subjects and in patients with COPD. Am J Respir Crit Care Med 1996; 153: 288-293.

22. Drexler H, Riede U, Munzel T, et al. Alterations of skeletal muscle in chronic heart failure. Circulation 1992; 85: 1751-1759.

23. Lipkin DP, Jones DA, Round JM, et al. Abnormalities of skeletal muscle in patients with chronic heart failure. Int J Cardiol 1988; 18: 187-195.

24. Casaburi R, Patessio A, loli F, et al. Reductions in exercise lactic acidosis and ventilation as a result of exercise training in patients with obstructive lung disease. Am Rev Respir Dis 1991; 143: 9-18.

25. Maltais F, LeBlanc $P$, Whittom $F$, et al. Oxidative enzyme activities of the vastus lateralis muscle and the functional status in patients with COPD. Thorax 2000; 55: 848-853.

26. Matsumura $\mathrm{N}$, Nishijima $\mathrm{H}$, Kojima $\mathrm{S}$, et al. Determination of anaerobic threshold for assessment of functional state in patients with chronic heart failure. Circulation 1983; 68: 360-367.

27. Weber KT, Kinasewitz GT, Janicki JS, et al. Oxygen utilization and ventilation during exercise in patients with chronic cardiac failure. Circulation 1982; 65: 1213-1223.

28. Brum PC, Bacurau AV, Medeiros A, et al. Aerobic exercise training in heart failure: impact on sympathetic hyperactivity and cardiac and skeletal muscle function. BrazJ Med Biol Res 2011; 44: 827-835.

29. Roveda F, Middlekauff HR, Rondon MU, et al. The effects of exercise training on sympathetic neural activation in advanced heart failure: a randomized controlled trial. J Am Coll Cardiol 2003; 42: 854-86o.

30. Vogiatzis I, Simoes DC, Stratakos G, et al. Effect of pulmonary rehabilitation on muscle remodelling in cachectic patients with COPD. Eur Respir J 2010; 36: 301-310.

31. Giannuzzi P, Temporelli PL, Corra U, et al. Antiremodeling effect of long-term exercise training in patients with stable chronic heart failure: results of the Exercise in Left Ventricular Dysfunction and Chronic Heart Failure (ELVD-CHF) Trial. Circulation 2003; 108: 554-559.

32. Nici L, Donner C, Wouters E, et al. American Thoracic Society/European Respiratory Society statement on pulmonary rehabilitation. Am J Respir Crit Care Med 2006; 173: 1390-1413.

33. Vogiatzis I. Strategies of muscle training in very severe COPD patients. Eur Respir J 2011; 38: 971-975.

34. Vogiatzis I, Nanas S, Roussos C. Interval training as an alternative modality to continuous exercise in patients with COPD. Eur Respir J 2002; 20: 12-9.

35. Wisloff U, Stoylen A, Loennechen JP, et al. Superior cardiovascular effect of aerobic interval training versus moderate continuous training in heart failure patients: a randomized study. Circulation 2007; 115: 3086-3094.

36. Vogiatzis I, Terzis G, Nanas S, et al. Skeletal muscle adaptations to interval training in patients with advanced COPD. Chest 2005; 128: 3838-3845.

37. Coronado M, Janssens JP, De MB, et al. Walking activity measured by accelerometry during respiratory rehabilitation. J Cardiopulm Rehabil 2003; 23: 357-364.

38. Dallas MI, McCusker C, Haggerty MC, et al. Using pedometers to monitor walking activity in outcome assessment for pulmonary rehabilitation. Chron Respir Dis 2009; 6: 217-224.

39. Steele BG, Belza B, Hunziker J, et al. Monitoring daily activity during pulmonary rehabilitation using a triaxial accelerometer. J Cardiopulm Rehabil 2003; 23: 139-142.

40. Gary RA, Cress ME, Higgins MK, et al. Combined aerobic and resistance exercise program improves task performance in patients with heart failure. Arch Phys Med Rehabil 2011; 92: 1371-1381.

41. Mercken EM, Hageman G), Schols AM, et al. Rehabilitation decreases exercise-induced oxidative stress in chronic obstructive pulmonary disease. Am J Respir Crit Care Med 2005; 172: 994-1001.

42. Sewell L, Singh SJ, Williams JE, et al. Can individualized rehabilitation improve functional independence in elderly patients with COPD? Chest 2005; 128: 1194-1200.

43. Walker PP, Burnett A, Flavahan PW, et al. Lower limb activity and its determinants in COPD. Thorax 2008; 63: 683-689.

44. Spruit MA, Pitta F, Garvey C, et al. Differences in content and organisational aspects of pulmonary rehabilitation programmes. Eur Respir J 2014; 43: 1326-1337.

45. Keating A, Lee A, Holland AE. What prevents people with chronic obstructive pulmonary disease from attending pulmonary rehabilitation? A systematic review. Chron Respir Dis 2011; 8: 89-99.

46. Holland AE, Hill C), Rochford P, et al. Telerehabilitation for people with chronic obstructive pulmonary disease: Feasibility of a simple, real time model of supervised exercise training. J Telemed Telecare 2013; 19: 222-226.

47. Stickland $M$, Jourdain T, Wong EY, et al. Using telehealth technology to delivery pulmonary rehabilitation in chronic obstructive pulmonary disease patients. Can Respir J 2011; 18: 216-220.

48. Goldstein RS, O'Hoski S. Telemedicine in COPD: Time to pause. Chest 2014; 145: 945-949.

49. Tousignant M, Marquis N, Page C, et al. In-home telerehabilitation for older persons with chronic obstructive pulmonary disease: A pilot study. Telerehab 2012; 4: 7-13.

50. Sato $N$, Origuchi $H$, Yamamoto $U$, et al. The importance of daily physical activity for improved exercise tolerance in heart failure patients with limited access 
to centre-based cardiac rehabilitation. Exp Clin Cardiol 2012; 17: 121-124.

51. Piotrowicz E, Baranowski R, Bilinska M, et al. A new model of home-based telemonitored cardiac rehabilitation in patients with heart failure: effectiveness, quality of life, and adherence. EurJ Heart Fail 2010; 12: 164-171.

52. Lundell S, Holmner Å, Rehn B, et al. Telehealthcare in COPD: a systematic review and meta-analysis on physical outcomes and dyspnea. Respir Med 2015; 109: 11-26.

53. Pedone C, Chiurco D, Scarlata S, et al. Efficacy of multiparametric telemonitoring on respiratory outcomes in elderly people with COPD: a randomized controlled trial. BMC Health Serv Res 2013; 13: 82.

54. Paneroni M, Colombo F, Papalia A, et al. Is telerehabilitation a safe and viable option for patients with COPD? A feasibility study. COPD 2014; doi: 10.3109/15412555.2014.933794.

55. Barberan-Garcia A, Vogiatzis I, Solberg HS, et al. Effects and barriers to deployment of telehealth wellness programs for chronic patients across 3 European countries. Respir Med 2014; 108: 628-637.

56. Segrelles Calvo G, Gómez-Suárez C, Soriano JB, et al. A home telehealth program for patients with severe
COPD: the PROMETE study. Respir Med 2014; 108: 453-462.

57. Polisena J, Tran K, Cimon K, et al. Home telehealth for chronic obstructive pulmonary disease: A systematic review and meta-analysis. J Telemed Telecare 2010; 16: 120-127.

58. Seibert PS, Whitmore TA, Patterson C, et al. Telemedicine facilitates $\mathrm{CHF}$ home health care for those with systolic dysfunction. Int J Telemed Appl 2008; 235031. doi: $10.1155 / 2008 / 235031$.

59. Inglis SC, Clark RA, McAlister FA, et al. Structured telephone support or telemonitoring programmes for patients with chronic heart failure. Cochrane Database Syst Rev 2010; 4: doi: 10.1002/14651858. CDoo7228.

6o. Myers S, Grant RW, Lugn NE, et al. Impact of homebased monitoring on the care of patients with congestive heart failure. Home Health Care Manage Pract 2006; 18: 444-451.

61. Cruz J, Brooks D, Marques A. Home telemonitoring in COPD: a systematic review of methodologies and patients' adherence. Int J Med Inform 2014; 83: 249-263.

62. Whitten P, Mickus MJ. Home telecare for COPD/CHF patients: outcomes and perceptions. J Telemed Telecare 2007; 13: 69-73. 